\title{
Cokrigagem na estimativa dos teores de Ca e Mg em um Latossolo Vermelho distroférrico ${ }^{1}$
}

\author{
Cokriging to estimate levels of calcium and magnesium in a Rhodic Hapludox
}

Eduardo Leonel Bottega ${ }^{2 *}$, Samuel de Assis Silva ${ }^{2}$, Marcelo Marques Costa ${ }^{2}$ e Simone Priscila Bottega ${ }^{3}$

\begin{abstract}
Resumo - Buscou-se, com este estudo, estimar, através do uso da cokrigagem, valores de cálcio e magnésio, utilizando como co-variável valores de pH. Em um Latossolo Vermelho Distroférrico, amostrou-se a camada de 0-0,2 m, utilizando grade de 25 × 25 m, totalizando 60 pontos em 5,02 ha. Realizou-se, inicialmente, análise descritiva e de correlação e, posteriormente, análise geoestatística, para identificar a dependência espacial das variáveis estudadas. Utilizando a técnica da cokrigagem, os valores de $\mathrm{pH}$ mostraram-se eficientes na estimativa de teores de $\mathrm{Ca}$ e $\mathrm{Mg}$, devido a elevada correlação entre esta co-variável e as variáveis a serem estimadas.
\end{abstract}

Palavras-chave - Latossolos. Geoestatística. Variograma Cruzado. Teor de Cálcio. Teor de Magnésio.

\begin{abstract}
Sought, with this study, estimating, through the use of cokriging, values of calcium and magnesium, using as covariate $\mathrm{pH}$. In a Rhodic Hapludox, sampled the layer of 0-0.2 m, using the grid of $25 \times 25 \mathrm{~m}$, totaling 60 points from 5.02 ha. Was held, initially, descriptive analysis and correlation, and subsequently, geostatistical analysis to identify the spatial dependence of variables. Using the technique of cokriging $\mathrm{pH}$ values were efficient in the estimation of $\mathrm{Ca}$ and $\mathrm{Mg}$, due to the high correlation between this covariate and the variables to be estimated.
\end{abstract}

Key words - Geostatistics. Cross-variogram. Correlation. Calcium and Magnesium content.

\footnotetext{
*Autor para correspondência

'Recebido para publicação em 28/06/2010; aprovado em 25/04/2011

Pesquisa desenvolvida pela Faculdade de Ciências Agrárias da Universidade Federal da Grande Dourados/UFGD

${ }^{2}$ Programa de pós-graduação em Engenharia Agrícola, Universidade Federal de Viçosa/UFV, Viçosa-MG, Brasil, 36.570-000, eduardobottega@hotmail.com,samuel-assis@hotmail.com,marcelo.marques.costa@gmail.com

Programa de pós-graduação em Agronomia, UFGD, Dourados-MS, Brasil, 79.804-970, sibottega@hotmail.com
} 


\section{Introdução}

O cálcio tem importante função no solo, sendo essencial para que os microrganismos transformem os restos de cultura em húmus, libere os nutrientes, melhore a estrutura e a capacidade de retenção de água dos solos (LOPES, 1984). O magnésio é absorvido pela planta na forma iônica da solução do solo e acessado pelas raízes principalmente pelos mecanismos de interceptação radicular e fluxo de massa. A absorção de magnésio está associada também às suas relações de equilíbrio com cálcio e potássio na solução do solo (NOVAIS et al., 2007).

Segundo Silva e Chaves (2001), com exceção do $\mathrm{pH}$ dos solos, os atributos químicos apresentam maior variação que as propriedades físicas. $\mathrm{O}$ conhecimento da variação de atributos químicos é importante para o levantamento e manejo do solo, planejamento de esquemas de amostragem e gerenciamento de práticas agrícolas. Antes de buscar qualquer relação destes elementos com a cultura, é importante avaliar a extensão e a intensidade da dependência espacial desta variação, isoladamente ou em conjunto com outros parâmetros (GANDAH, 2000).

A variabilidade espacial dos solos é resultado de processos pedogenéticos e pode ser demonstrada por resultados dos levantamentos e análises, bem como pelas diferenças encontradas nas produções das plantas (SILVA et al., 2010). Segundo esses autores, a cokrigagem descreve a variação espacial e/ou temporal simultânea de duas variáveis aleatórias, que estão fortemente associadas entre si, portanto, é utilizada quando existe dependência espacial para cada variável em estudo e também entre as variáveis, tornando possível utilizar esta técnica na estimativa de valores não amostrados. Tal dependência espacial entre as amostras somente pode ser modelada por meio da geoestatística (WEBSTER, 2000).

Várias são as aplicações utilizando a cokrigagem. Silva et al. (2010) estimaram os níveis de atributos químicos do solo em função de atributos físicos. Boezio et al., (2006) realizaram o mapeamento do nível de água, a partir da topografia do terreno. Carvalho e Queiroz (2002) estimaram a distribuição espacial de precipitação pluvial média anual, usando altitude como co-variável.

Considerando a existência de correlação entre os atributos $\mathrm{pH}$, cálcio e magnésio e utilizando as técnicas estatística e geoestatística, buscou-se através deste estudo, estimar os valores de cálcio e magnésio, utilizando como co-variável valores de $\mathrm{pH}$ de um Latossolo Vermelho distroférrico.

\section{Material e métodos}

O experimento foi instalado na fazenda experimental da Faculdade de Ciências Agrárias da Universidade Federal da Grande Dourados, município de Dourados, MS, em um Latossolo Vermelho distroférrico textura argilosa (EMBRAPA, 2006), classe representativa da maioria dos solos do Centro-Sul do estado. A caracterização química e física do solo estudado é apresentada na Tabela 1.

Foi delimitada uma área experimental de 5,02 ha $(150 \times 335 \mathrm{~m})$. A grade amostral utilizada foi composta por 60 pontos espaçados regularmente em $25 \times 25 \mathrm{~m}$ (FIG. 1) e georreferenciados, utilizando um receptor GPS, com correção diferencial, modelo Promark 2. As coordenadas obtidas foram corrigidas no programa computacional Astec Solutions ${ }^{\circledR}$, fornecido pelo fabricante, e o arquivo utilizado como base para correção diferencial foi obtido no site do IBGE, relativo à estação da Rede Brasileira de Monitoramento Contínuo (RBMC), localizada em Campo Grande/MS e o datum utilizado foi o SIRGAS 2000.

As amostras de solo foram coletadas da camada 0-0,2 m, utilizando-se trato tipo holandês. Cada amostra foi composta por três subamostras simples, coletadas em um raio médio de $0,5 \mathrm{~m}$ do ponto conhecido. Os atributos avaliados foram o $\mathrm{pH}$ (em água), determinado utilizando a relação 1:2,5, Ca e $\mathrm{Mg}\left(\mathrm{mmol}_{\mathrm{c}} \mathrm{dm}^{-3}\right)$, determinados utilizando extrator $\mathrm{KCl}$ na concentração de $1 \mathrm{~mol} \mathrm{~L}^{-1}$.

Inicialmente, os dados foram submetidos a uma análise descritiva, exploratória e também a analise de

Tabela 1 - Atributos químicos e físicos do solo da área de estudo

\begin{tabular}{ccc}
\hline Atributos & Unidade & Valor \\
\hline $\mathrm{pH}\left(\mathrm{em} \mathrm{H}_{2} \mathrm{O}\right)$ & - & 6 \\
$\mathrm{~K}^{+}$ & $\mathrm{mmol}_{\mathrm{c}} \mathrm{dm}^{-3}$ & 6 \\
$\mathrm{Al}^{3+}$ & - & 1 \\
$\mathrm{Ca}^{2+}$ & - & 47 \\
$\mathrm{Mg}^{2+}$ & - & 45 \\
$\mathrm{H}^{+}+\mathrm{A}^{3+}$ & - & 63 \\
$\mathrm{SB}$ & - & 98 \\
$\mathrm{CTC}$ & - & 161 \\
$\mathrm{~V}$ & $\%$ & 60 \\
$\mathrm{P}$ & $\mathrm{mg} \mathrm{dm}^{-3}$ & 21 \\
$\mathrm{MO}$ & $\mathrm{g} \mathrm{dm}^{-3}$ & 37 \\
Areia & $\mathrm{g} \mathrm{kg}^{-1}$ & 350 \\
Silte & $\mathrm{g} \mathrm{kg}^{-1}$ & 90 \\
Argila & $\mathrm{g} \mathrm{kg}^{-1}$ & 560 \\
\hline
\end{tabular}




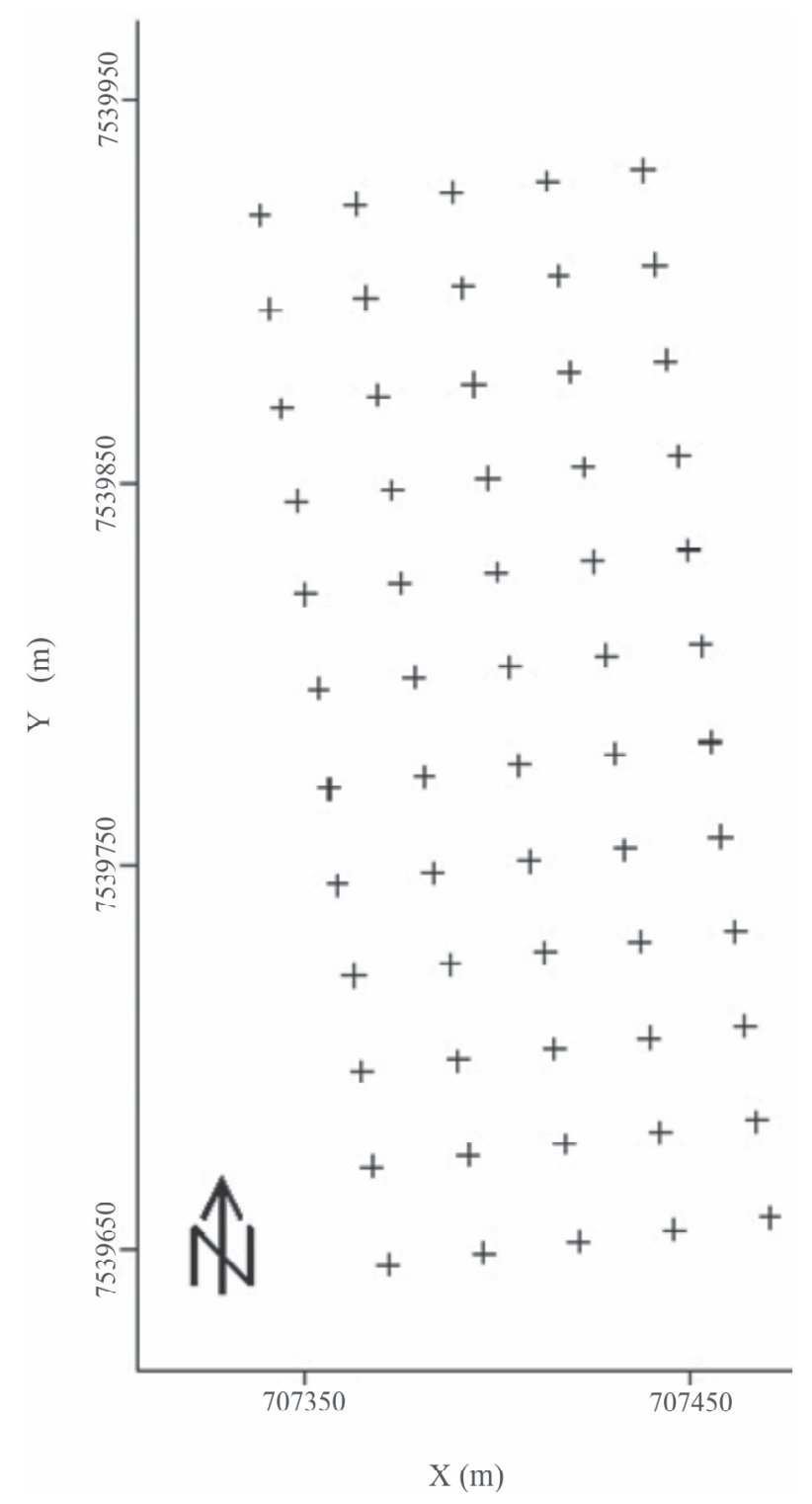

Figura 1 - Grade amostral utilizada na área experimental

correlação para determinar a relação entre as variáveis. Para a determinação de valores discrepantes (outliers), foram analisados os quartis superiores e inferiores e testada a normalidade pelo teste Shapiro-Wilk's a 5\% de probabilidade $(\mathrm{W})$.

Para verificar a dependência espacial das variáveis, foi empregada a análise geoestatística, segundo Vieira (2000). Foram construídos variogramas, partindo das pressuposições de estacionaridade da hipótese intrínseca e do cálculo da semivariância , estimada conforme equação 1 :

$y(h)=\frac{1}{2 N(h)} \sum_{i-1}^{N(h)}[z(x i)-z(x i+h)]^{2}$
Em que $N(h)$ é o número de pares experimentais de observações $Z(x i) e Z(x i+h)$, separados por uma distância $\mathrm{h}$. $\mathrm{O}$ variograma é representado pelo gráfico $\gamma(h)$ versus $h$.

Do ajuste de um modelo matemático aos valores calculados de $\hat{y}(h)$, foram estimados os coeficientes do modelo teórico para o variograma (o efeito pepita, $\mathrm{C}_{0}$; patamar, $\mathrm{C}_{0}+\mathrm{C}$ e o alcance, a).

A escolha do modelo baseou-se no menor valor da soma dos quadrados dos resíduos (SQR) e maior coeficiente de determinação múltipla $\left(\mathrm{R}^{2}\right)$ do ajuste dos modelos teóricos aos variogramas experimentais e da validação cruzada (valores observados versus valores estimados).

O índice de dependência espacial (IDE), que é a proporção em porcentagem do efeito pepita $\left(\mathrm{C}_{0}\right)$ em relação ao patamar $\left(\mathrm{C}_{0}+\mathrm{C}\right)$, foi calculado usando a equação 2 , de acordo com Cambardella et al. (1994), e apresenta a seguinte proporção: (a) dependência forte $<25 \%$; (b) dependência moderada de 26 a $75 \%$, (c) dependência fraca $>75 \%$ e (d) independência entre as amostras quando a relação for igual a $100 \%$.

$\operatorname{IDE}=\left(\frac{\mathrm{C}_{0}}{\mathrm{C}_{0}+\mathrm{C}}\right) \times 100$

Para espacialização de $\mathrm{Ca}$ e $\mathrm{Mg}$, em função dos valores de $\mathrm{pH}$ do solo, utilizou-se a extensão multivariada da krigagem, conhecida como cokrigagem. Esta estimativa pode ser mais precisa do que a krigagem de uma variável simples, quando o variograma cruzado mostrar dependência entre as duas variáveis (VIEIRA, 2000).

$\mathrm{Na}$ cokrigagem (VIEIRA, 2000), para estimar valores, $\mathrm{Z}_{2}{ }^{*}$, para qualquer local, $\mathrm{X}_{0}$, o valor estimado deve ser uma combinação linear de ambos $Z_{1}$ e $Z_{2}$, ou seja:

$$
\mathrm{Z}_{2} *\left(\mathrm{x}_{0}\right)=\sum_{\mathrm{i}=1}^{\mathrm{N} 1} \lambda_{1 \mathrm{i}} \mathrm{z}\left(\mathrm{x}_{1 \mathrm{i}}\right)+\sum_{\mathrm{j}=1}^{\mathrm{N} 2} \lambda_{2 \mathrm{j}} \mathrm{z}_{2}\left(\mathrm{x}_{2 \mathrm{j}}\right)
$$

Em que $\mathrm{N}_{1}$ e $\mathrm{N}_{2}$ são os números de vizinhos de $\mathrm{Z}_{1}$ e $Z_{2}$, respectivamente, e $1_{1}$ e $1_{2}$ são os pesos associados a cada valor de $Z_{1}$ e $Z_{2}$. Tomando $z_{1}\left(x_{1 i}\right)$ e $z_{2}\left(x_{2 j}\right)$ como sendo uma realização das funções aleatórias $Z_{1}\left(X_{1 i}\right)$ e $\mathrm{Z}_{2}\left(\mathrm{X}_{2 \mathrm{j}}\right)$, respectivamente, e assumindo estacionaridade de ordem 2, o estimador pode ser rescrito em:

$$
\mathrm{Z}_{2} *\left(\mathrm{x}_{0}\right)=\sum_{\mathrm{i}=1}^{\mathrm{N} 1} \lambda_{1 \mathrm{i}} \mathrm{z}\left(\mathrm{X}_{1 \mathrm{i}}\right)+\sum_{\mathrm{j}=1}^{\mathrm{N} 2} \lambda_{2 \mathrm{j}} \mathrm{Z}_{2}\left(\mathrm{X}_{2 \mathrm{j}}\right)
$$

Expressando que a estimativa da variável $Z_{2}$ deverá ser uma combinação linear de ambos $Z_{1}$ e $Z_{2}$, com os pesos $\lambda_{1}$ e $\lambda_{2}$ distribuídos de acordo com a 
dependência espacial de cada uma das variáveis entre si e a correlação cruzada entre elas.

A análise geoestatística, bem como os métodos de interpolação, foram realizadas no software GS+, versão 7. Os mapas foram confeccionados utilizando o software Surfer, versão 8.

\section{Resultados e discussão}

$\mathrm{Na}$ Tabela 2, são apresentados os valores da estatística descritiva e valores relacionados ao teste de normalidade para as variáveis $\mathrm{pH}$, cálcio $(\mathrm{Ca})$ e magnésio $(\mathrm{Mg})$. Foi observado normalidade dos dados para todas as variáveis testadas, bem como correlação entre elas. Pode-se observar que os dados apresentam distribuição simétrica, com proximidade entre os valores de média e mediana, e os valores do coeficiente de assimetria próximos de zero, concordando com estudos realizados por Souza et al. (2004), Roque et al. (2005) e Silva et al. (2007). O menor coeficiente de variação $(\mathrm{CV})$ foi observado para os valores de $\mathrm{pH}(6,9 \%)$, considerado baixo $(<12 \%)$. Já para as variáveis $\mathrm{Ca}$ e $\mathrm{Mg}$, observa-se, respectivamente, valores de $21,2 \%$ e $22,5 \%$, considerados médios ( 12 a 24\%). Os dados não apresentaram nenhum CV\% considerado alto (>24\%), segundo critério de classificação para o coeficiente de variação (CV), proposto por Warrick e Nielsen (1980). Silva et al. (2007), em estudo da variabilidade espacial de atributos químicos do solo, encontraram valor semelhantes. Valores elevados de CV podem ser considerados como os primeiros indicadores da existência de heterogeneidade nos dados (FROGBROOK et al., 2002).

Na Tabela 3, são apresentados valores referentes aos parâmetros dos variogramas para cada variável analisada (efeito pepita, $\mathrm{C}_{0}$; patamar, $\mathrm{C}_{0}+\mathrm{C}$; alcance, a; e o coeficiente de determinação, $\mathrm{R}^{2}$ ), valores referentes ao índice de dependência espacial (IDE\%) e os modelos teóricos que melhor se ajustaram a variabilidade espacial dos dados e a Figura 2 apresenta os variogramas dos modelos teóricos ajustados a distribuição espacial das variáveis $\mathrm{pH}, \mathrm{Ca}$ e $\mathrm{Mg}$.
Observa-se, na Tabela 3, que as variáveis $\mathrm{pH}, \mathrm{Ca}$ e $\mathrm{Mg}$ apresentaram forte dependência espacial ( $>25 \%$ ), ajustando-se ao modelo esférico. Carvalho et al. (2003), Souza et al. (2003), Silva et al. (2003), Cavalcante et al. (2007) e Souza et al. (2004), estudando a variabilidade espacial de atributos químicos, obtiveram resultados semelhantes. $\mathrm{O}$ alcance apresentado pelas variáveis foi de 86,2; 88,3 e 88,6; respectivamente. Todas as variáveis apresentaram também um elevado coeficiente de determinação $\left(\mathrm{R}^{2}\right)$, o que demonstra que o modelo escolhido foi eficiente ao modelar a dependência especial das variáveis. Todas as variáveis apresentaram proporção $\left(\mathrm{C}_{0}+\mathrm{C} / \mathrm{C}_{0}\right)$ semelhante para $\mathrm{o}$ valor de efeito pepita $(4,25 ; 4,44 ; 4,4$; respectivamente). Guimarães (2004) destaca que quanto menor for a proporção do efeito pepita para o patamar do variograma, maior a continuidade do fenômeno, menor a variância da estimativa e maior a confiança que se pode ter na estimativa.

A Tabela 4 apresenta valores referentes aos parâmetros dos variogramas cruzados ( $\mathrm{pH}$ x Ca e pH x Mg), bem como os valores referentes ao índice de dependência espacial (IDE\%) e os modelos teóricos que melhor se ajustaram para cada relação. A Figura 3 apresenta os variogramas cruzados das variáveis $\mathrm{pH}$ x Ca e $\mathrm{pH} \times \mathrm{Mg}$.

Observa-se que os valores dos parâmetros dos variogramas, bem como os modelos, são semelhantes, indicando que estes seguem o mesmo padrão de distribuição espacial. Se analisarmos os valores de efeito pepita $\left(\mathrm{C}_{0}=0,63\right.$ para $\mathrm{pH} \times \mathrm{Ca}$ e $\mathrm{C}_{0}=0,62$ para $\mathrm{pH} \times \mathrm{Mg}$ ), constatamos o elevado grau de dependência espacial entre as variáveis, uma vez que quanto menor o efeito pepita, mais forte é a dependência espacial do atributo em questão. A presença de ajuste de modelo teórico aos variogramas cruzados, afirma a possibilidade de utilização da variável $\mathrm{pH}$ como variável auxiliar na obtenção de estimativas de valores de $\mathrm{Ca}$ e $\mathrm{Mg}$ em lugares não amostrados dentro da área de estudo, facilitando e reduzindo os custos de análise e amostragem, o que corrobora com estudos realizados por Silva et al. (2010), que buscaram estimar, por meio do método de cokrigagem, os níveis de fósforo no solo utilizando as frações granulométricas como variáveis auxiliares.

Tabela 2 - Estatística descritiva e teste de normalidade para as variáveis $\mathrm{pH}, \mathrm{Ca}$ e $\mathrm{Mg}$

\begin{tabular}{lccccccccccc}
\hline \multirow{2}{*}{ Variáveis } & \multicolumn{10}{c}{ Valores } \\
\cline { 2 - 12 } & Média & Mediana & Mín. & Máx. & CV $(\%)$ & s & Cs & Ck & w & R \\
\hline $\mathrm{pH}$ & 5,89 & 5,9 & 5 & 6,7 & 6,9 & 0,41 & $-0,08$ & $-0,90$ & $\mathrm{~ns}$ & $1,00^{*}$ \\
$\mathrm{Ca}$ & 47,07 & 48 & 21 & 66 & 21,2 & 9,96 & $-0,47$ & 0,10 & $\mathrm{~ns}$ & $0,92^{*}$ \\
$\mathrm{Mg}$ & 44,41 & 45 & 18 & 63 & 22,5 & 9,99 & $-0,48$ & 0,12 & $\mathrm{~ns}$ & $0,92^{*}$ \\
\hline
\end{tabular}

pH em água; Ca e Mg em mmol dm-3; Min. = mínimo; Max. = máximo; s = desvio padrão; CV(\%)= coeficiente de variação; Cs = coeficiente de simetria; Ck = coeficiente de curtose; $\mathrm{W}^{\text {ns }}$ distribuição normal pelo teste Shapiro-Wilk's a 5\% de significância; $\mathrm{R}^{*}$ coeficiente de correlação de Pearson significativo $(p<0,05)$ 
Tabela 3 - Parâmetros, índice de dependência espacial (IDE\%) e modelos teóricos ajustados dos variogramas

\begin{tabular}{lccc}
\hline \multirow{2}{*}{ Parâmetros } & \multicolumn{3}{c}{ Variáveis } \\
\cline { 2 - 4 } & $\mathrm{pH}$ & $\mathrm{Ca}$ & $\mathrm{Mg}$ \\
\hline Efeito Pepita $\left(\mathrm{C}_{0}\right)$ & 0,04 & 23,1 & 23,5 \\
Patamar $\left(\mathrm{C}_{0}+\mathrm{C}\right)$ & 0,17 & 102,6 & 103,4 \\
Alcance $(\mathrm{a})$ & 86,2 & 88,3 & 88,6 \\
$\mathrm{R}^{2}$ & 0,7 & 0,7 & 0,7 \\
$\mathrm{IDE}(\%)$ & 23,5 (forte) & 22,5 (forte) & 22,7 (forte) \\
\hline Modelo & Esférico & Esférico & Esférico \\
\hline
\end{tabular}
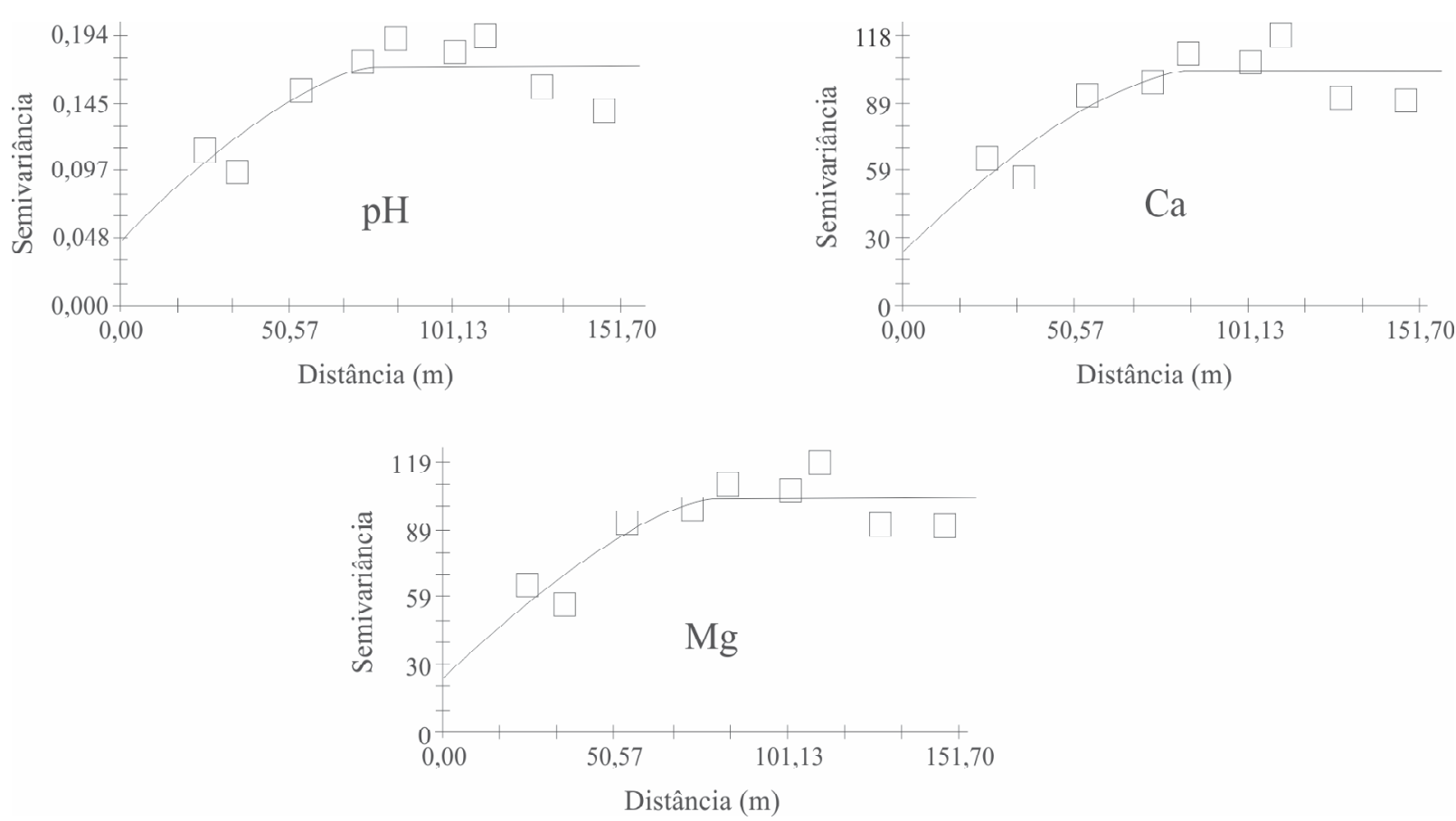

Figura 2 - Variogramas dos modelos teóricos ajustados a distribuição espacial das variáveis $\mathrm{pH}, \mathrm{Ca}$ e $\mathrm{Mg}$

Tabela 4 - Parâmetros, índice de dependência espacial (IDE\%) e modelos ajustados dos variogramas cruzados

\begin{tabular}{lcc}
\hline \multirow{2}{*}{ Parâmetros } & \multicolumn{2}{c}{ Variáveis } \\
\cline { 2 - 3 } & $\mathrm{pH} \mathrm{x} \mathrm{Ca}$ & $\mathrm{pH} \mathrm{x} \mathrm{Mg}$ \\
\hline Efeito Pepita $\left(\mathrm{C}_{0}\right)$ & 0,63 & 0,62 \\
Patamar $\left(\mathrm{C}_{0}+\mathrm{C}\right)$ & 3,91 & 3,91 \\
Alcance $(\mathrm{a})$ & 84,5 & 84,3 \\
$\mathrm{R}^{2}$ & 0,70 & 0,70 \\
IDE $(\%)$ & 16,1 (forte) & 15,8 (forte) \\
\hline Modelo & Esférico & Esférico \\
\hline
\end{tabular}

As Figuras 4 e 5 apresentam, respectivamente, os mapas da distribuição espacial das variáveis $\mathrm{pH}, \mathrm{Ca} \mathrm{e}$ $\mathrm{Mg}$ e os mapas de $\mathrm{Ca}$ e $\mathrm{Mg}$, estimados por cokrigagem, utilizando valores de $\mathrm{pH}$ como co-variável.

Os mapas da distribuição espacial dos valores de $\mathrm{pH}, \mathrm{Ca}$ e $\mathrm{Mg}$ (FIG. 4) se apresentam semelhantes, em relação ao padrão de ocorrência, mostrando que as variáveis apresentaram mesmo padrão de dependência espacial na área em estudo. Resultados semelhantes foram encontrados por Souza et al. (2004), os autores explicam que, para o entendimento das causas da variabilidade do solo, é preciso conhecer os processos do solo que operam em locais específicos.

Observa-se, pela semelhança entre os mapas da distribuição espacial dos teores de $\mathrm{Ca}$ e $\mathrm{Mg}$, a possibilidade 


\section{E. L. Bottega et al.}

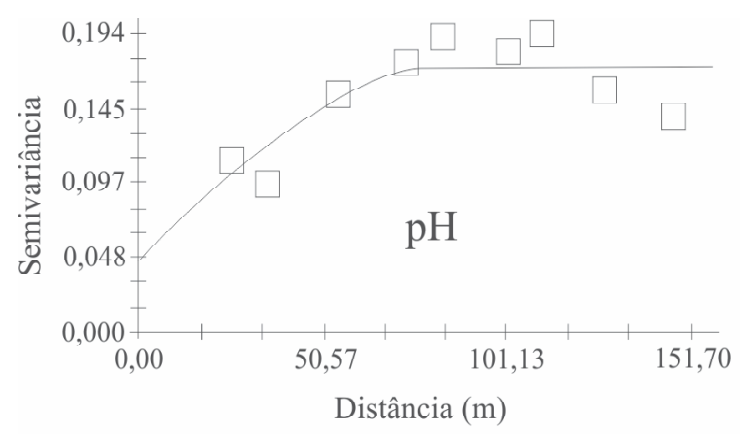

Figura 3 - Variogramas cruzados das variáveis pH x Ca e pH x Mg

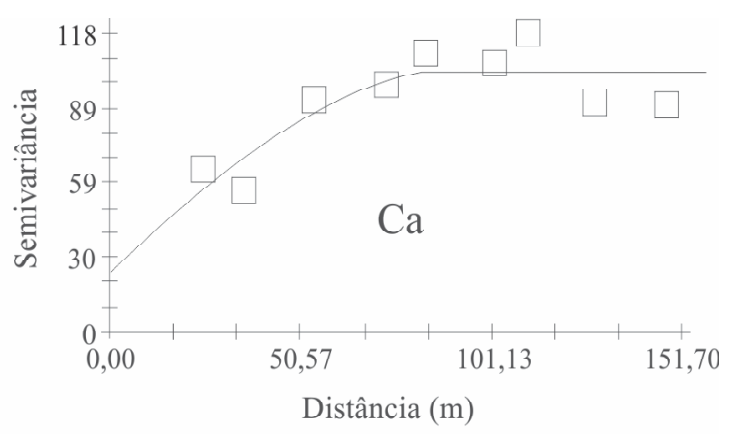

Distância (m)
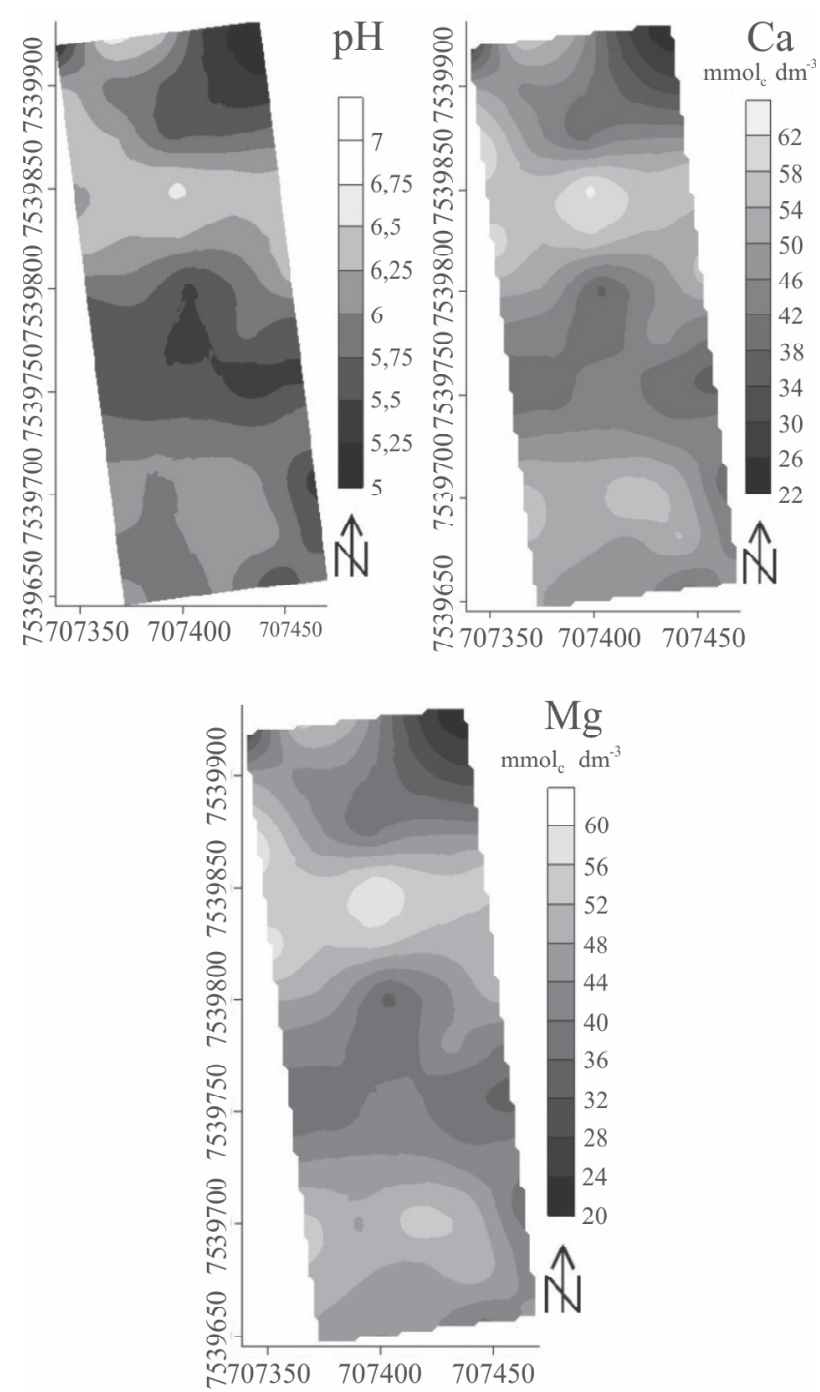

Figura 4 - Mapa da distribuição espacial das variáveis $\mathrm{pH}, \mathrm{Ca}$ e $\mathrm{Mg}$

de reduzir o número de análises de solo para estes nutrientes, desde que se utilize valores de $\mathrm{pH}$ como co-variável para a estimativa de tais variáveis, assim, não se perde a
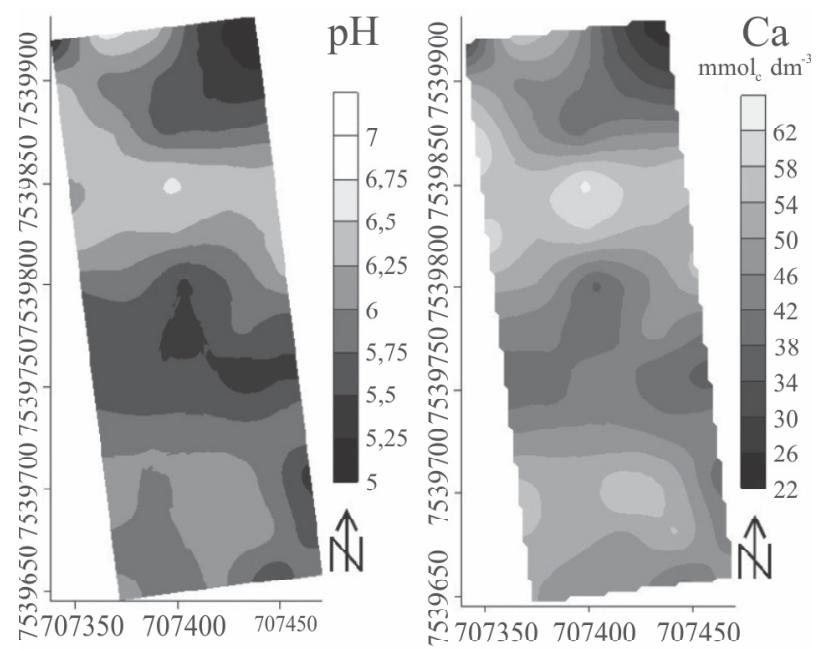

Figura 5 - Mapas da distribuição espacial dos teores de $\mathrm{Ca}$ e $\mathrm{Mg}$ estimados por cokrigagem utilizando valores de $\mathrm{pH}$ como co-variável

eficiência da caracterização química do solo. Resultados semelhantes foram observados por Angelico (2006), estudando o desempenho da cokrigagem na determinação da variabilidade de atributos do solo ( $\mathrm{pH}$ e $\mathrm{Mn}$ em função dos níveis de MO), e Silva et al. (2010). A utilização do $\mathrm{pH}$ como co-variável, na estimativa de teores de $\mathrm{Ca}$ e $\mathrm{Mg}$, é possível, pois ambos estão fortemente correlacionados $(\mathrm{R}=0,92)$. Isso pode ser explicado por estudos realizados por Oliveira et al. (2005), onde os autores destacam que a origem da acidez do solo é causada, principalmente, por lixiviação de $\mathrm{Ca}$ e $\mathrm{Mg}$ do solo pela água da chuva ou irrigação, bem como pela remoção dos nutrientes pelas colheitas. Estudos conduzidos por Fernandes et al. (2008) evidenciam tal relação do $\mathrm{pH}$ com $\mathrm{Ca}$ e $\mathrm{Mg}$, os autores, estudando as alterações na fertilidade do solo, na nutrição mineral e na produtividade da bananeira irrigada por dez anos, concluíram que a aplicação da água calcária resultou em forte elevação do $\mathrm{pH}$ e da condutividade elétrica do solo, incrementando teores de $\mathrm{Ca}$ e $\mathrm{Mg}$ veiculado pela irrigação. 

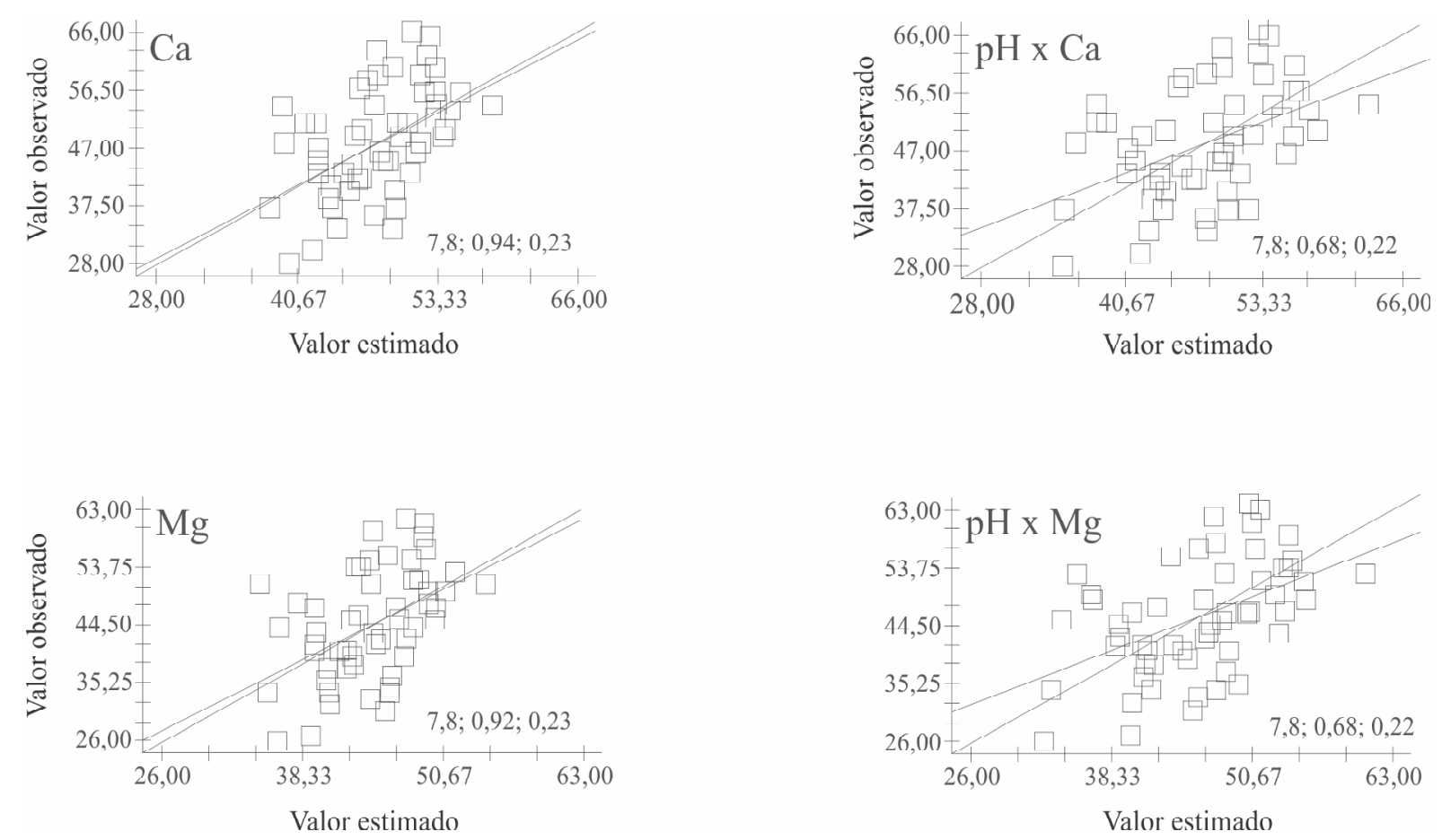

Figura 6 - Gráficos de validação cruzada e parâmetros de ajuste: erro quadrático de predição (SE); coeficiente de regressão e coeficiente de determinação $\left(\mathrm{r}^{2}\right)$

A Figura 6 apresenta os gráficos de validação cruzada das estimativas das variáveis $\mathrm{Ca}$ e $\mathrm{Mg}$ e das estimativas das mesmas variáveis utilizando valores de pH como co-variável. O melhor ajuste foi obtido para estimativas de valores absolutos de $\mathrm{Ca}$ e $\mathrm{Mg}$, isso pode ser comprovado ao observarmos o coeficiente de regressão da reta, que, quanto mais próximo ao valor um, melhor é o ajuste. Porém, ao observarmos a validação cruzada para valores de $\mathrm{Ca}$ e $\mathrm{Mg}$ obtidos, utilizando valores de $\mathrm{pH}$ como co-variável, observados que pouca foi a diferença, mais uma vez confirmando a possibilidade da utilização de valores de $\mathrm{pH}$ para a estimativa de valores de $\mathrm{Ca}$ e $\mathrm{Mg}$.

\section{Conclusões}

1. Foi possível, através do uso da cokrigagem, utilizando valores de $\mathrm{pH}$ como co-variável, estimar, com boa confiabilidade, valores de $\mathrm{Ca}$ e $\mathrm{Mg}$ na área em estudo.

2. A cokrigagem se mostra como uma boa opção para estimativa de variáveis de difícil amostragem, seja por sua complexidade ou pelo elevado custo de análise, desde que se observe uma boa correlação entre a co-variável e a variável a ser estimada.

\section{Referências}

ANGELICO, J. C. Desempenho da cokrigagem na determinação da variabilidade de atributos do solo. Revista Brasileira de Ciência do Solo, v. 30, n. 06, p. 931-936, 2006.

BOEZIO, M. N. M. Cokrigagem colocada aplicada ao mapeamento do nível de água subterrânea. REM: Revista Escola de Minas, v. 59, n. 02, p. 159-164, 2006.

CAMBARDELLA, C. A. et al. Field scale variability of soil properties in central Iowa soil. Soil Science Society of America Journal, v. 58, p. 1501-1511, 1994.

CARVALHO, J. R. P.; QUEIROZ, E. F. Uso de cokrigagem colocalizada na determinação da distribuição espacial de precipitação. Campinas: Embrapa Informática Agropecuária, 2002. (Comunicado Técnico, 21).

CARVALHO, M. P. et al. Variabilidade espacial de atributos de um solo sob videira em Vitória Brasil (SP). Revista Brasileira de Ciência do Solo, v. 27, n. 04, p. 695-703, 2003.

CAVAlCANTE, E. G. S. et al. Variabilidade espacial de atributos químicos do solo sob diferentes usos e manejos. Revista Brasileira de Ciência do Solo, v. 31, p. 1329-1339, 2007.

EMPRESABRASILEIRADEPESQUISAAGROPECUÁRIA (EMBRAPA). Centro Nacional de Pesquisa de Solos. Sistema Brasileiro de Classificação de Solos. Rio de Janeiro: Embrapa, 2006. 412 p. 
FERNANDES, L. A. et al. Fertilidade do solo, nutrição mineral e produtividade da bananeira irrigada por dez anos. Pesq. Agropec. Bras., Brasília, v. 43, n. 11, p. 1575-1581, nov. 2008.

FROGBROOK, Z. L. et al. Exploring the spatial relations between cereal yield and soil chemical properties and the implications for sampling. Soil Use and Management, v. 18, n. 01, p. $1-9,2002$.

GANDAH, M. Dynamics of spatial variability of millet growth and yields at three sites in Niger, west Africa and implications for precision agriculture research. Agricultural Systems, v. 63, n. 02, p. 123-140, 2000.

GUIMARÃES, E. C. Geoestatística básica e aplicada. Universidade Federal de Uberlândia, 2004. 78 p. v. 1.

LOPES, A. S. Solos sob cerrado: características, propriedades e manejo. 2. ed. Piracicaba-SP: POTAFOS, 1984. 162 p.

NOVAIS, R. F. et al. Fertilidade do solo. Viçosa: Sociedade Brasileira de Ciência do Solo, 2007. 741 p.

OLIVEIRA, I. P. et al. Considerações sobre a acidez dos solos de cerrado. Revista Eletrônica Faculdade Montes Belos, GoiásGO. v. 1, n. 1, p. 01-12, ago. 2005.

ROQUE, C. G. et al. Variabilidade espacial de atributos químicos em Argissolo Vermelho-Amarelo cultivado com seringueira. Revista de Ciências Agro-Ambientais, v. 03, p. 26-45, 2005.

SILVA, F. M. et al. Variabilidade espacial de atributos químicos e de produtividade na cultura do café. Ciência Rural, v. 37, n. 02, p. 401-407, 2007.
SILVA, P. C. M.; CHAVES, L. H. G. Avaliação e variabilidade espacial de fósforo, potássio e matéria orgânica em Alissolos. Revista Brasileira de Engenharia Agrícola e Ambiental, v. 05, n. 03, p. 431-436, 2001.

SILVA, S. A. et al. Variabilidade espacial do fósforo e das frações granulométricas de um Latossolo Vermelho Amarelo. Revista Ciência Agronômica, v. 41, n. 01, p. 1-8, 2010.

SILVA, V. R. et al. Variabilidade das características químicas do solo e produtividade de milho em um Argissolo Vermelho Amarelo distrófico arênico. Revista Brasileira de Ciência do Solo, v. 27, n. 06, p. 1013-1020, 2003.

SOUZA, C. K. et al. Influência do relevo na variação anisotrópica dos atributos químicos e granulométricos de uma latossolo em JaboticabalSP. Engenharia Agrícola, v. 23, n. 03, p. 486-495, 2003.

SOUZA, Z. M. et al. Variabilidade espacial do $\mathrm{pH}, \mathrm{Ca}, \mathrm{Mg}$ e V\% do solo em diferentes formas do relevo sob cultivo de cana-deaçúcar. Ciência Rural, v. 34, n. 06, p. 1763-1771, 2004.

VIEIRA, S. R. Geoestatistica em estudos de variabilidade espacial do solo. In: NOVAIS, R. F. et al. (Ed.). Tópicos em ciência do solo. Vicosa: Sociedade Brasileira de Ciencia do Solo, 2000. p. 1-53. v. 1.

WEBSTER, R. Is soil variation random? Geoderma, v. 97, n. 03/04, p. $149-163,2000$.

WARRICK, A. W.; NIELSEN, D. R. Spatial variability of soil physical properties in the field. In: HILLEL, D. (Ed). Applications of soil physics. New York: Academic, 1980. cap. 2, p. 319-344. 